\title{
Effect of Soil Structure Interaction on Torsional Response of Structure Supported by Asymmetric Soil Foundation System
}

\author{
Fangyuan Zhou, ${ }^{1}$ Xuezhang Wen, ${ }^{2}$ and Hongping $\mathrm{Zhu}^{1}$ \\ ${ }^{1}$ School of Civil Engineering and Mechanics, Huazhong University of Science and Technology, Wuhan, Hubei 430074, China \\ ${ }^{2}$ College of Civil Engineering, Hunan University, Changsha, Hunan 410082, China \\ Correspondence should be addressed to Xuezhang Wen; wenxuezhang630@gmail.com
}

Received 4 August 2015; Revised 30 November 2015; Accepted 2 December 2015

Academic Editor: Nerio Tullini

Copyright (C) 2016 Fangyuan Zhou et al. This is an open access article distributed under the Creative Commons Attribution License, which permits unrestricted use, distribution, and reproduction in any medium, provided the original work is properly cited.

\begin{abstract}
The torsional response of a structure supported by asymmetric foundation was investigated in this study. Several types of the asymmetric soil foundation system were employed to analyze the effect of soil structure interaction on torsional response of the superstructure. It can be concluded from the study that torsional response would be generated for a structure supported by asymmetric soil foundation system under horizontal seismic excitation, and the generated torsional response of the superstructure changed with the degree of the asymmetry of the foundation.
\end{abstract}

\section{Introduction}

In recent decades, several reports have pointed out that structure failures due to torsional response were common during previous earthquake $[1,2]$. Meanwhile, through numerical analysis of the structure under seismic excitation, researchers found that asymmetric structures were subjected to more damage than symmetric structures. Chandler and Hutchinson [3] presented a detailed parametric study of the coupled lateral and torsional responses of a partially symmetric single storey building subjected to both harmonic and earthquake base excitation. It was concluded that torsional coupling induced a significant amplification of earthquake forces which should be accounted for in design. de La Llera and Chopra [4-6] calculated the value of the accidental eccentricity with the equivalent lateral force procedure by studying the dynamic response of single and multistory buildings subjected to torsional ground motion. Nagarajaiah et al. [7, 8], using multistory models, concluded that eccentricities in the isolation system and superstructure both contributed to the torsional response. Similarly Jangid and Datta $[9,10]$ found that significant eccentricity of the superstructure could reduce the effectiveness of the base isolation system. In TenaColunga et al. [11-13], parametric study was carried out with eccentricities in both the isolation system and superstructure, which concluded that eccentricity in the isolation system might lead to a torsional response. Most of these studies assumed base fixity in the structural models, neglecting the soil structure interaction (SSI).

Some studies showed that soil structure interaction considerably influenced the dynamic responses of the structures subjected to earthquake loading [14-16]. Although currently there exist adequate computational capabilities for building design, SSI analyses were rarely carried out for the seismic design of building structures [17].

Neglecting SSI in the seismic response analysis of building structures may result in a false torsional response of the structure. In many cases, fixed-base analyses cannot predict accurately the torsional response of building structures. As we know the soil properties and the foundation type can change the dynamic response of the superstructure. Thus, the assumption that the base of the structure is fixed is not realistic. Therefore, several researchers attempted to incorporate the flexibility of foundation in asymmetric system models. Among them, Balendra et al. [18] used simple springs to approximate the foundation impedance in an asymmetric multistory structure. Chandler and Hutchinson $[19,20]$ analyzed the seismic responses subjected to different types of earthquake loading considering soil structure interaction. Sivakumaran et al. [21] and Sivakumaran and Balendra [22] 


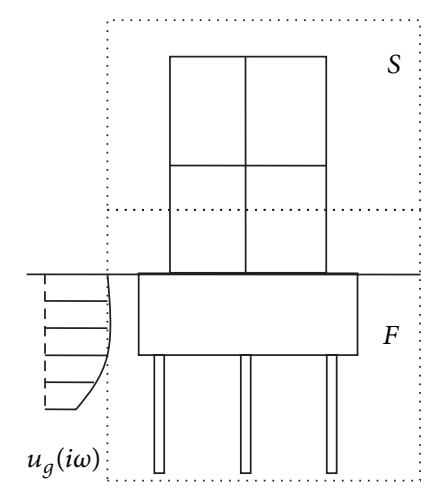

FIGURE 1: Structure-foundation-soil system.

inspected the dynamic response of asymmetric multistorey structure-foundation systems using frequency independent foundation impedance.

Previous studies mainly focused on the torsional responses of structures induced by the asymmetry in superstructures. Little attention has been paid to the torsional responses of structures induced by asymmetric soil foundation system. In this study, the torsional response of a structure supported on asymmetric soil foundation system was investigated. Several types of asymmetric soil foundation were employed to analyze the effect of soil structure interaction on the torsional response of the superstructure.

\section{Analytical Theory}

The analysis procedure in this paper was based on the following basic assumptions:

(1) the soil was assumed to be elastic medium;

(2) the foundation remains in close contact with the surrounding soil; no slippage was allowed at the soil foundation interface.

For a structure (Figure 1) under seismic excitation, the equation of motion of the structure considering soil structure interaction can be depicted as formula (1) (the calculation was performed in the frequency domain, and the term $e^{i \omega t}$ is omitted in the formula):

$$
\left[\begin{array}{ll}
{\left[S_{S S}\right]} & {\left[S_{S F}\right]} \\
{\left[S_{F S}\right]} & {\left[S_{F F}\right]}
\end{array}\right]\left\{\begin{array}{l}
\left\{u_{S}\right\} \\
\left\{u_{F}\right\}
\end{array}\right\}=\left\{\begin{array}{l}
\left\{P_{S}\right\}^{F} \\
\left\{P_{F}\right\}^{F}
\end{array}\right\},
$$

where $[S]=(1+2 \xi i)[K]-\omega^{2}[M] .[K],[M]$, and $\{u\}$ are the stiffness matrices, mass matrices, and displacement vector, respectively. Subscripts $S$ and $F$ represent the superstructure and foundation, respectively. $\xi$ represents the damping ratio. $\left\{P_{S}\right\}^{F}$ and $\left\{P_{F}\right\}^{F}$ stand for the force vector acting at the superstructure and the foundation, respectively. For the seismic wave input problem, the force vector acting at the superstructure $\left\{P_{S}\right\}^{F}=\{0\}$.

For the superstructure, the well-known beam model is one of the most commonly used models for conducting

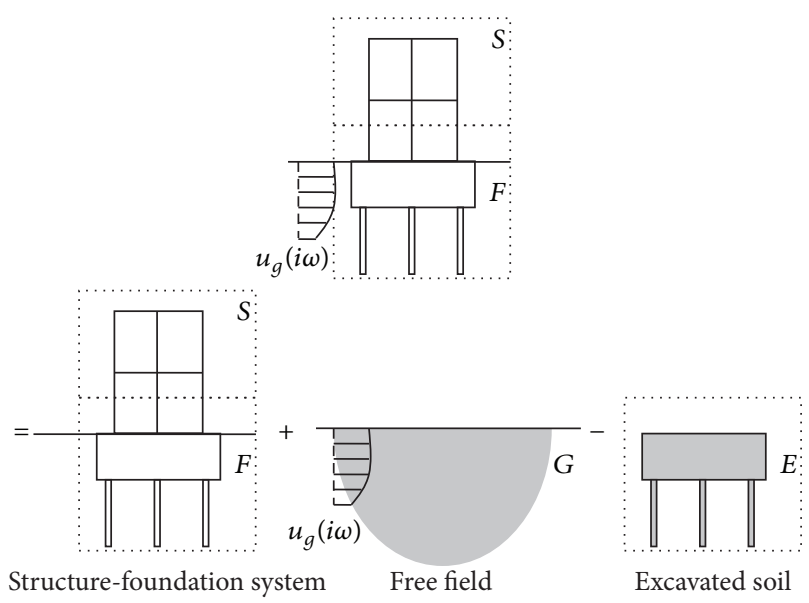

FIGURE 2: Structure-foundation-soil system based on the substructure method.

comprehensive parametric studies. In the MDOF structure models used in this study, each floor was assumed to be a lumped mass connected by a beam element. The stiffness matrices of the foundation and excavated soil were obtained by finite element method.

As shown in Figure 2, the structure-foundation-soil system was separated into three components, that is, structurefoundation, the free field, and excavated soil, using the concept of the substructure method [23].

The equation of motion of the free field can be depicted as the formula

$$
\left[K_{F}\right]^{G}\left(\left\{u_{F}\right\}-\left\{u_{G}\right\}\right)=\left\{P_{F}\right\}^{G},
$$

where character $G$ represents the free field, $\left\{P_{F}\right\}^{G}$ stands for the force vector acting at the nodes of the free field.

The stiffness matrix $\left[K_{F}\right]^{G}$ of the free field can be calculated with the following equations:

$$
\begin{aligned}
{\left[K_{F}\right]^{G}=} & {[G]^{-1}, } \\
{[G] } & =\left[\begin{array}{cccc}
{\left[\delta_{11}\right]} & {\left[\delta_{12}\right]} & \cdots & {\left[\delta_{1 n}\right]} \\
{\left[\delta_{21}\right]} & {\left[\delta_{22}\right]} & \cdots & {\left[\delta_{2 n}\right]} \\
\vdots & \vdots & \ddots & \vdots \\
{\left[\delta_{n 1}\right]} & {\left[\delta_{n 2}\right]} & \cdots & {\left[\delta_{n n}\right]}
\end{array}\right] .
\end{aligned}
$$

In (4), Green's function solution for a concentrated load and for a uniform distributed load acting on a disk (when the excitation node and reception node coincide with each other) was applied to form the flexibility matrix of the free field $\left[\delta_{i j}\right]$ [24] (see Appendix A). At the same time, a paraxial boundary condition (see Appendix A) $[25,26]$ was used to simulate the bottom boundary of the layered soil.

The equation of motion of excavated soil can be depicted as the formula

$$
\left[S_{F F}\right]^{E}\left\{u_{F}\right\}=\left\{P_{F}\right\}^{E},
$$


where $\left[S_{F F}\right]^{E}=(1+2 \xi i)\left[K_{F F}\right]^{E}-\omega^{2}[M]^{E}$. Superscript $E$ stands for the excavated soil which has same geometric dimension as the foundation and same physical parameters as the free field.

For the soil structure interaction system,

$$
\left\{P_{F}\right\}^{F}+\left\{P_{F}\right\}^{G}-\left\{P_{F}\right\}^{E}=0 .
$$

Substituting formulae (1) (5) into formula (6) produces

$$
\begin{aligned}
& {\left[\begin{array}{cc}
{\left[S_{S S}\right]} & {\left[S_{S F}\right]} \\
{\left[S_{F S}\right]} & {\left[S_{F F}\right]^{F}-\left[S_{F F}\right]^{E}+[G]^{-1}}
\end{array}\right]\left\{\begin{array}{l}
\left\{u_{S}\right\} \\
\left\{u_{F}\right\}
\end{array}\right\}} \\
& \quad=\left\{\begin{array}{c}
0 \\
\left\{K_{F}\right\}^{G}\left\{u_{G}\right\}
\end{array}\right\} .
\end{aligned}
$$

Formula (7) is the equation of motion for a structurefoundation-soil system under seismic excitation. Through formula (7) the dynamic response of the structure under seismic excitation can be obtained.

\section{Numerical Study}

In order to investigate the torsional response of the structure influenced by asymmetric soil foundation system, influences of the following asymmetric soil foundation systems were analyzed:

(1) Embedded foundation supported by piles with nonunique pile lengths.

(2) L shape and T shape embedded foundation supported by piles.

(3) Foundation with an adjacent foundation.

For all the cases discussed in this section, normal incident $\mathrm{SH}$ wave was used as an excitation source; the frequency of the excitation wave ranged from $0.1 \mathrm{~Hz}$ to $10 \mathrm{~Hz}$.

A 10-storey structure was used in this section, the first, second, and third horizontal natural frequencies of the superstructure were $1.4,4.2$, and $6.8 \mathrm{~Hz}$, respectively. The first, second, and third torsional natural frequencies of the superstructures were 1.9, 5.7 and $9.4 \mathrm{~Hz}$, respectively.

\subsection{Embedded Foundation Supported by Piles with Nonunique} Pile Lengths. Plane sketch of the employed embedded foundation supported by piles of the superstructure was depicted in Figure 3. The dimension of the embedded foundation was $72 \mathrm{~m}$ in length $(2 D)$ and $54 \mathrm{~m}$ in width (2C) and buried depth of the foundation $(E)$ was $4 \mathrm{~m}$. Piles were defined by diameter $d(1.5 \mathrm{~m})$, center-to-center spacing between adjacent piles $S(9.0 \mathrm{~m})$, and length $L$. The material parameters of the pile were as follows: density $=2.4 \mathrm{t} / \mathrm{m}^{3}$; moduli of elasticity of the pile $=2.1 \times 10^{4} \mathrm{MPa}$; Poisson ratio of the pile $=1 / 6$. The soil condition surrounding the foundation was shown in Figure 4. To ensure the accuracy of the thin layer method at low frequency, the relationship between the wavelength $\lambda$ and the depth of the soil $H$ should be $\lambda / H \leq 4$. Meanwhile, to ensure the accuracy of the thin layer method at high

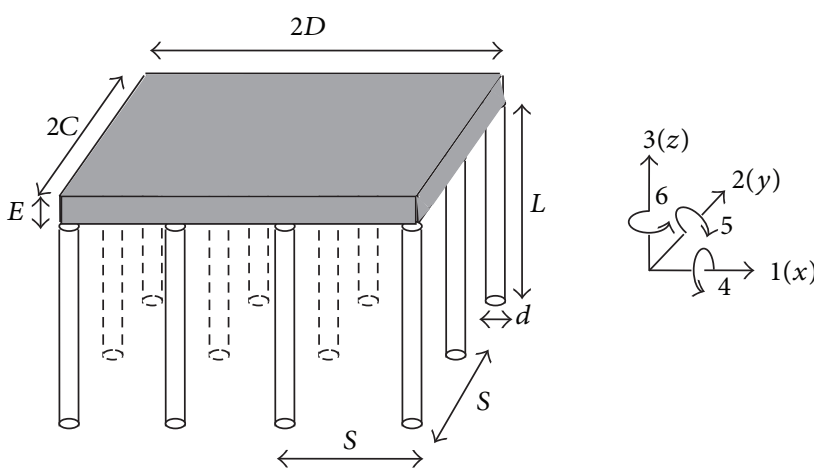

FIGURE 3: Sketch of the embedded foundation supported by piles.

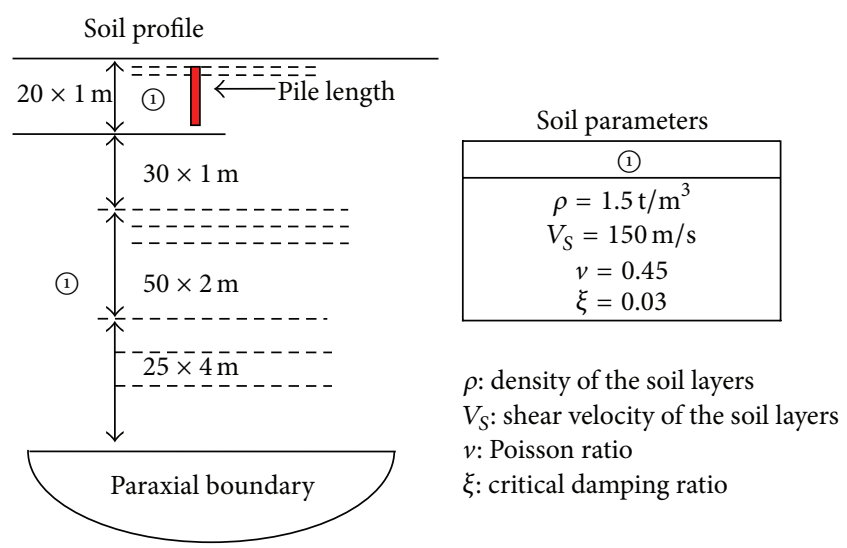

FIGURE 4: Soil condition.

frequency, the relationship between the wavelength $\lambda$ and the depth of the soil layer $H_{1}$ should be $\lambda / H_{1} \geq 6$ [27]. In this paper, the frequency domain of the excitation varied from $0.1 \mathrm{~Hz}$ to $10 \mathrm{~Hz}$; thus, the soil profile shown in Figure 4 was employed.

In order to investigate the impact of irregular soil foundation system on the torsional response of the superstructure, the following cases as shown in Figure 5 were investigated:

(1) Case 1: embedded foundation supported by piles with unique pile length.

(2) Cases 2 3: embedded foundation supported by piles with nonunique piles lengths (nonunique piles were distributed along $x$-axis).

(3) Cases 4 5: embedded foundation supported by piles with nonunique piles lengths (nonunique piles were distributed along $y$-axis).

The following ratio was employed to investigate the torsional response of the superstructure: $U_{6} D / U_{g}$. Here $U_{6}$ is the torsional response of the structure; $U_{g}$ is the lateral free field displacement.

Torsional response of the roof floor (RF) of the superstructure for Cases 1 5 is depicted in Figure 6. It can be observed that when the excited direction was perpendicular to $x$-axis, the torsional responses of the roof floor in Case 2 and Case 3 were generated, and the torsional response of 

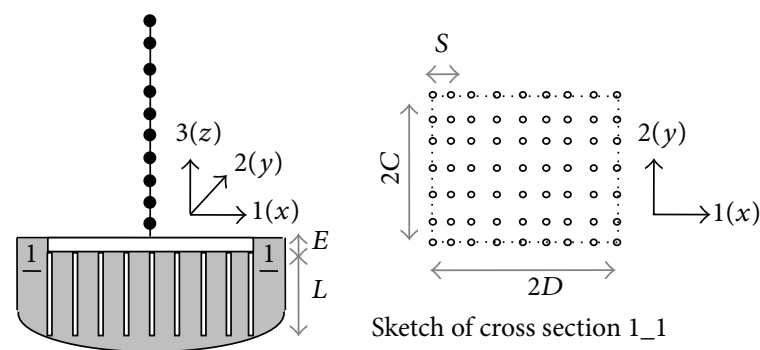

Sketch of cross section 1_1

Case 1: $L=16 \mathrm{~m}$

(a) Embedded foundation supported by piles with unique pile length
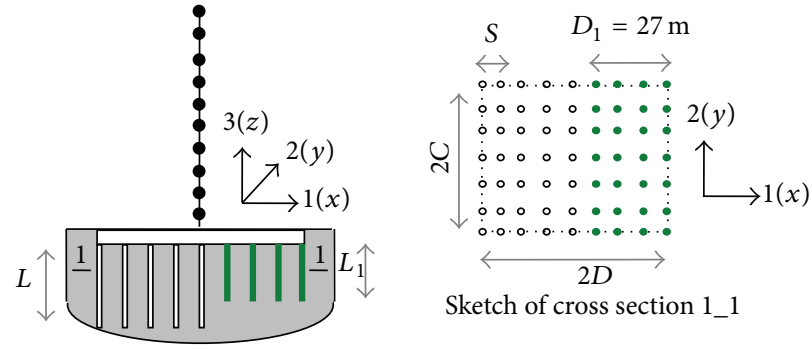

Sketch of cross section 1_1

(b) Embedded foundation supported by piles with nonunique pile length (nonunique piles distributed along $x$-axis)

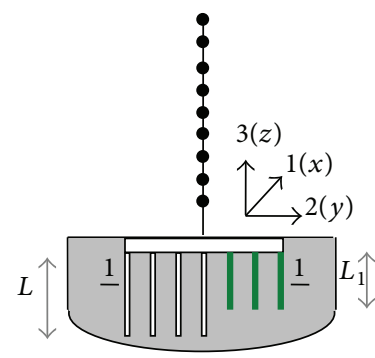

$\stackrel{S}{\leftrightarrow} D_{1}=18 \mathrm{~m}$

$0.0 \cdot 0 \cdot 0 . \leftrightarrow$

00000

क०००...

(1)

तิ

○०००...

$\longrightarrow 2(y)$

(3)

$\longleftrightarrow 2 \mathrm{C}$

Sketch of cross section 1_1

Case 4: $L=16 \mathrm{~m}, L_{1}=14 \mathrm{~m}$; Case 5: $L=16 \mathrm{~m}, L_{1}=8 \mathrm{~m}$

(c) Embedded foundation supported by piles with nonunique pile length (nonunique piles distributed along $y$-axis)

FIGURE 5: Embedded foundation supported by piles.

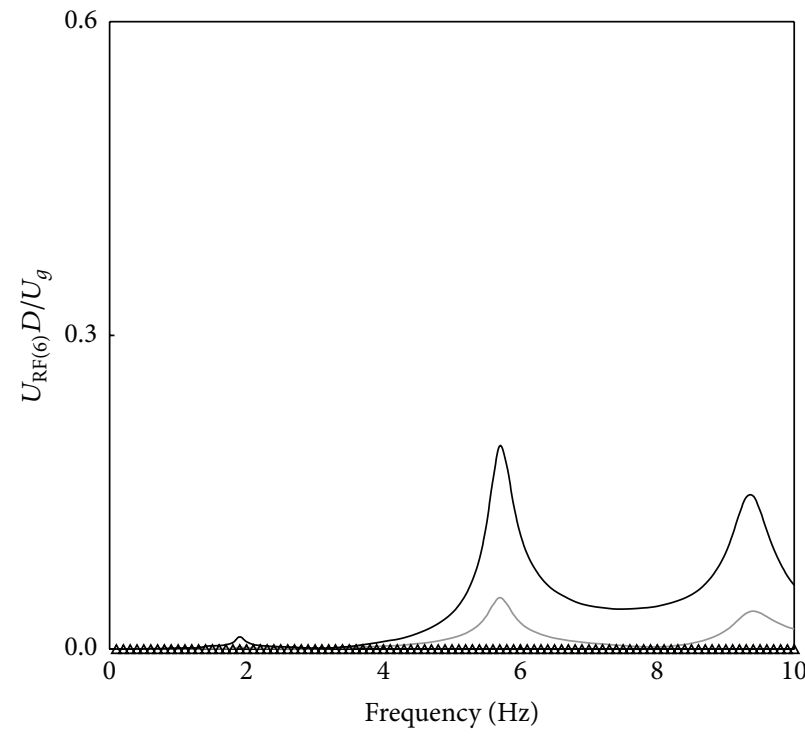

$\Delta \quad$ Case 1

$\triangle \quad$ Case 1

(a) Excited perpendicular to $x$ direction

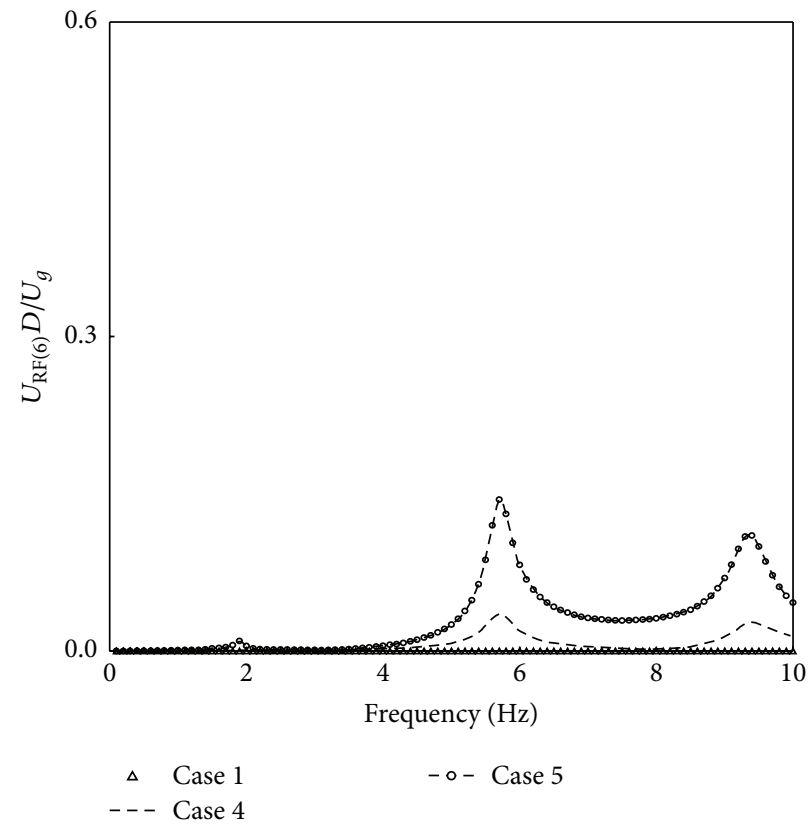

(b) Excited parallel to $x$ direction

FIgURE 6: Torsional response of the roof floor of the superstructure. 


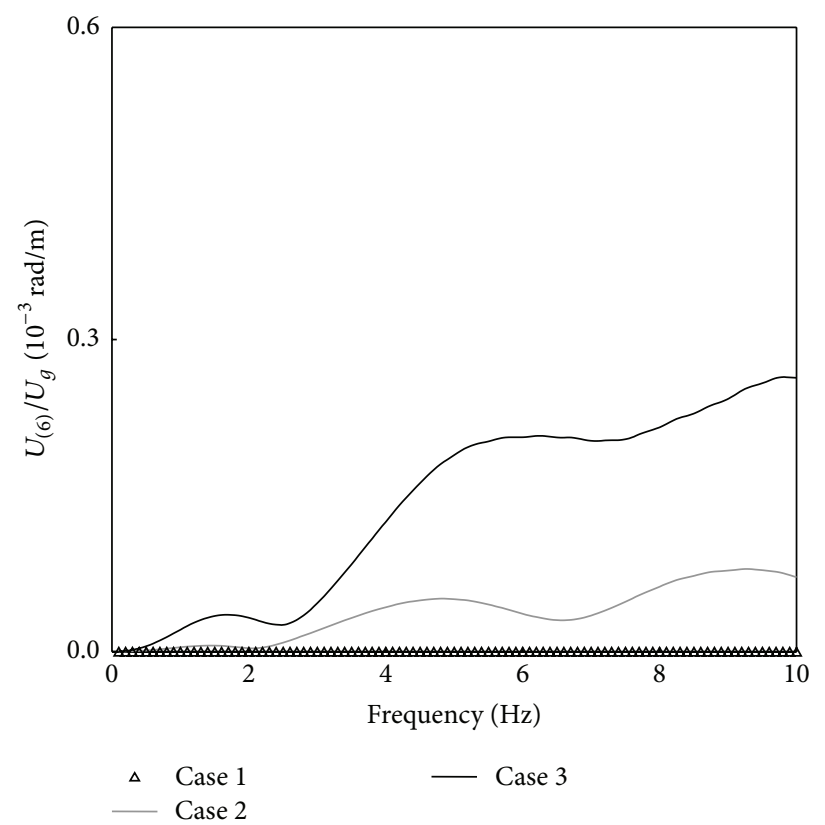

(a) Excited perpendicular to $x$ direction

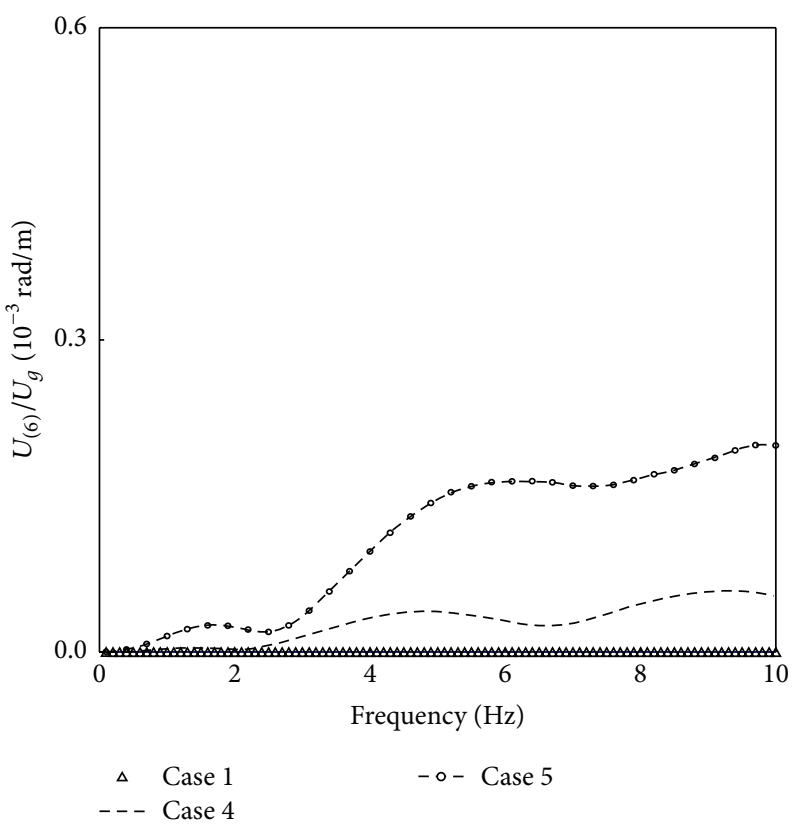

(b) Excited parallel to $x$ direction

FIGURE 7: Foundation input motion of the embedded foundation supported by piles.

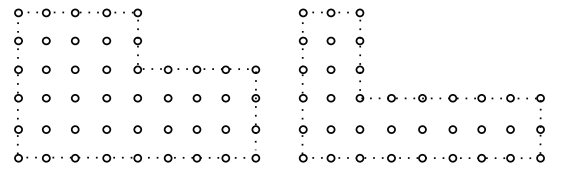

(a) Case 6: L shape (b) Case 7: L shape

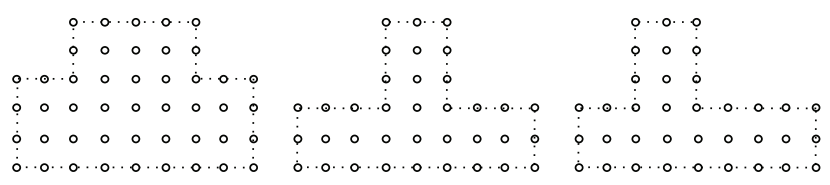

$\begin{array}{lll}\text { (c) Case 8: } \mathrm{T} \text { shape } & \text { (d) Case 9: } \mathrm{T} \text { shape } & \text { (e) Case 10: } \mathrm{T} \text { shape }\end{array}$

Figure 8: $\mathrm{L}$ shape and $\mathrm{T}$ shape embedded foundation supported by piles.

the roof floor in Case 4 and Case 5 occurred when the excited direction was parallel to the $x$-axis. However, the torsional response of the roof floor in Case 1 cannot be observed under both directions of horizontal excitation. Through Figures 6(a) and $6(\mathrm{~b})$, it can be seen that the torsional response of the roof floor increased with the length difference of the piles.

The above phenomenon can be explained as follows. When the embedded foundation was supported by piles with different pile lengths the mass center and the rigidity center of the soil foundation system did not coincide with each other; thus eccentricity existed in the soil foundation system. The foundation input motion of the embedded foundation supported by piles in Cases 1 5 is depicted in Figure 7. It can be concluded that in Case 1 (symmetric soil foundation system) torsional foundation input motion was not generated, but in Cases $2 \sim 5$ the torsional foundation input motion was generated due to the asymmetric soil foundation system. Therefore, the asymmetric soil foundation system can induce the torsional foundation input motion; thus for the structure supported by asymmetric soil foundation system, the torsional response of the superstructure is of concern.

\subsection{Shape and T Shape Embedded Foundation Supported by} Piles. Figure 8 shows the L shape (Cases 6 7) and T shape (Cases 8 10) embedded foundations supported by piles. The diameter and length of the piles used in this section were $1.5 \mathrm{~m}$ and $16 \mathrm{~m}$, respectively. The distance between the adjacent piles was $9 \mathrm{~m}$. The parameters of the superstructure and the soil were the same as those in Section 3.1. The plan dimension of the $\mathrm{L}$ shape and $\mathrm{T}$ shape embedded foundation supported by piles can be obtained through the distance between the two adjacent piles as shown in Figure 8. The torsional response of Cases $6 \sim 7$ is compared with that of Case 1 depicted in Figure 9(a). It can be observed from Figure 9(a) that for a 10-storey structure supported on L shape embedded foundation supported by piles, torsional response of the roof 

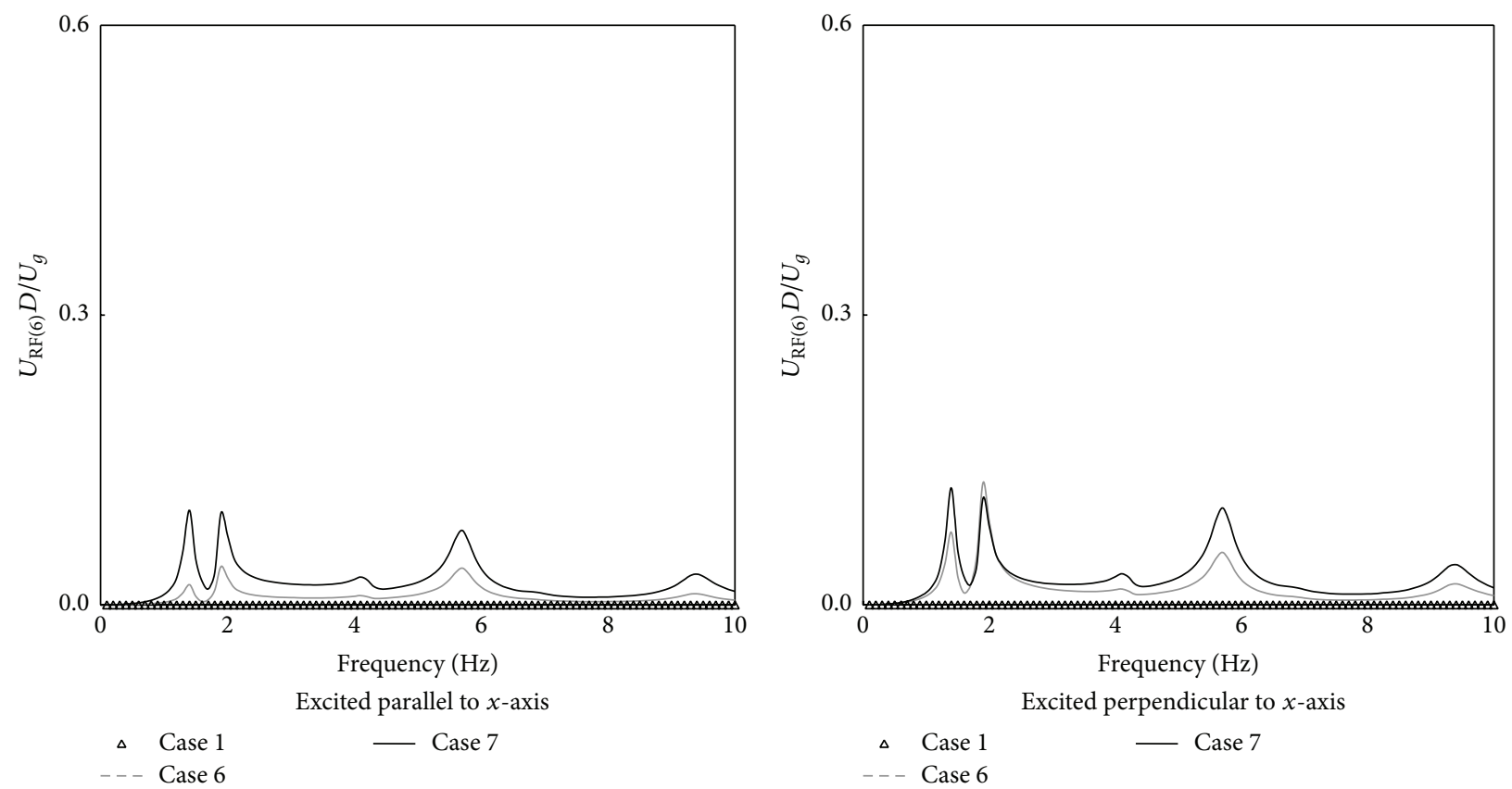

(a) L shape
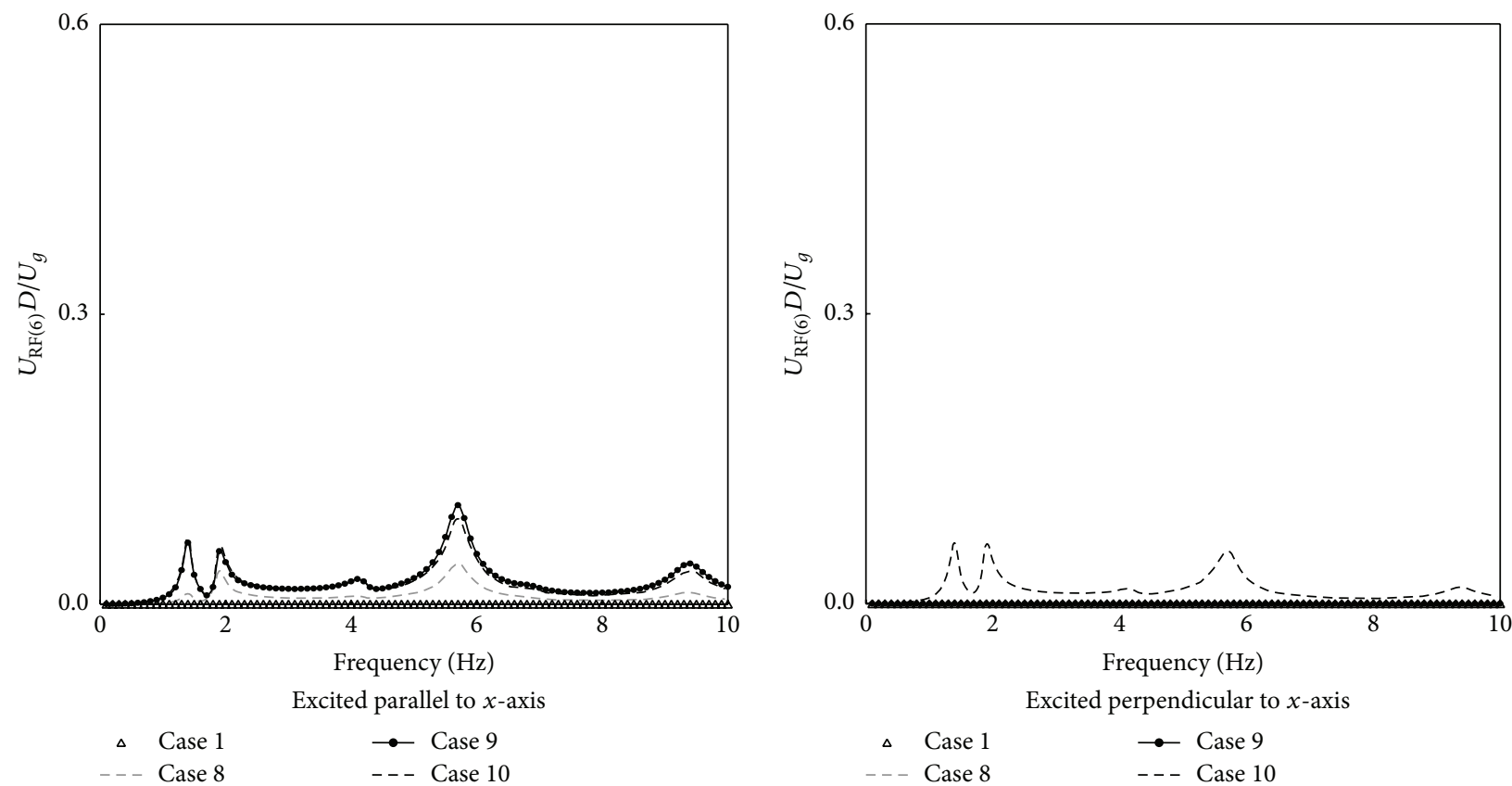

(b) T shape

FIgURE 9: Torsional response of the roof floor of the superstructure.

floor was generated regardless of the horizontal excitation direction, and it increased with the irregular degree of the L shape foundation. The torsional responses in Cases $8 \sim 10$ are compared with that of Case 1 depicted in Figure 9(b). From Figure 9(b), it can be concluded that the torsional response phenomenon can be observed in Cases $8 \sim 10$ when the excitation direction was parallel to $x$-axis. However, if the excitation direction was perpendicular to $x$-axis, there was torsional response in Case 10 but none in Case 8 and Case
9 because both the mass center and the rigidity center of the soil foundation system were on the $y$-axis.

3.3. Foundation with an Adjacent Foundation. The influence of an adjacent structure (named AS) on the torsional response of the targeted structure (named TS) is addressed in this section. The parameters of the soil were the same as those depicted in Figure 4. The dimension of the embedded foundation was $60 \mathrm{~m}$ in length $(2 D)$ and $60 \mathrm{~m}$ in width $(2 C)$ 

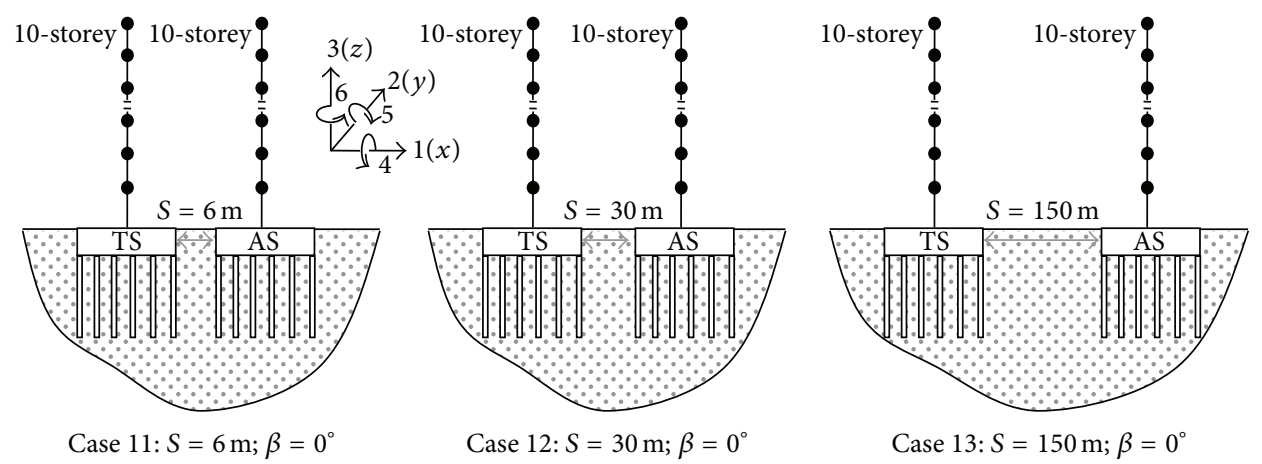

(a) Variation of distance $S$

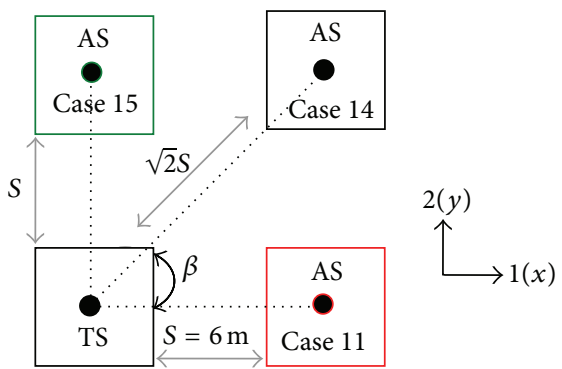

(b) Variation of angle $\beta$ (plan sketch)

FIGURE 10: Structure with an adjacent structure.

and the buried depth of the foundation $(E)$ was $4 \mathrm{~m}$. The material parameters of the pile were the same as those in Section 3.1. The diameter and the length of the piles were $1.5 \mathrm{~m}$ and $16 \mathrm{~m}$, respectively. The distance between the two adjacent piles was $12 \mathrm{~m}$. Figure 10(a) shows the sketch paragraph of a 10-storey structure (TS) adjacent to a 10-storey structure (AS) with varying distance ( $S$ ) between the two adjacent foundations. Figure 10(b) shows the sketch paragraph of a 10storey building (TS) adjacent to a 10-storey structure (AS) with varying placed angle $(\beta)$ between the two adjacent foundations. The following cases are discussed: Case 11: $S=$ $6 \mathrm{~m}, \beta=0^{\circ}$; Case 12: $S=30 \mathrm{~m}, \beta=0^{\circ}$; Case 13: $S=150 \mathrm{~m}$, $\beta=0^{\circ}$; Case 14: $S=6 \mathrm{~m}, \beta=45^{\circ}$; Case 15: $S=6 \mathrm{~m}, \beta=90^{\circ}$.

Torsional responses of the roof floor in Cases 11 13 compared with that in Case 1 (excited direction was perpendicular to the $x$-axis) are depicted in Figure 11(a). It can be observed that torsional response of the superstructure could be induced by the existence of the adjacent structure, and it increased with the decrease of the distance $S$. The above phenomenon can be explained as follows. As the movement of the soil around the foundation of the targeted structure can be restricted by the presence of an adjacent structure, motion characteristic of the soil around the targeted structure at different spatial location may be impacted in different extent. Thus, the torsional response of the roof floor of the targeted structure can be observed under horizontal seismic excitation.

In order to investigate the effect of the placed angle $\beta$ of the adjacent structure to the torsional response of the existing structure, comparison results between Case 11, Case 14, and Case 15 are depicted in Figure 11(b). It can be observed that when the excitation direction was parallel to the $x$-axis, the torsional responses of the roof floor of the TS in Cases 14 and 15 were generated, and if the excitation direction was perpendicular to the $x$-axis, the torsional responses of the roof floor of TS in Cases 11 and 14 occurred. Thus, it can be concluded that the torsional response of TS can be influenced by the placed angle of the adjacent structure (AS).

Figure 12 shows the response of a structure adjacent to another structure with varying storey numbers. The first horizontal natural frequencies of the four-, six-, and eightfloor structures were $3.2,2.3$, and $1.7 \mathrm{~Hz}$, respectively. And the first torsional natural frequencies of the four-, six-, and eight-floor structures were $4.5,3.2$, and $2.3 \mathrm{~Hz}$, respectively. Symbol 4_6 was used to represent a 4-storey structure (TS) adjacent to a 6-storey structure (AS). Figure 13(a) shows the torsional response of the TS affected by the adjacent structure with varying storey numbers in Case 19; it can be concluded that the torsional response of the roof of the structure can be affected by the adjacent structure, and when the targeted structure was adjacent to a structure with same structural and foundation configuration (Case $16\left(4 \_4\right)$ ), the torsional dynamic response of the targeted structure may be more severe than the other cases (Case 16 (4_6) and Case 16 (4_8)). Meanwhile, through Figure 13(a), it can also be observed that around the horizontal natural frequency of the adjacent structure the torsional response of the targeted structure was generated. In order to investigate the torsional dynamic response of the targeted structure affected by the horizontal natural frequency of the adjacent structure, two cases shown in Figures 12(b) 12(c) are discussed here. As it has been described that the first horizontal natural frequencies of 


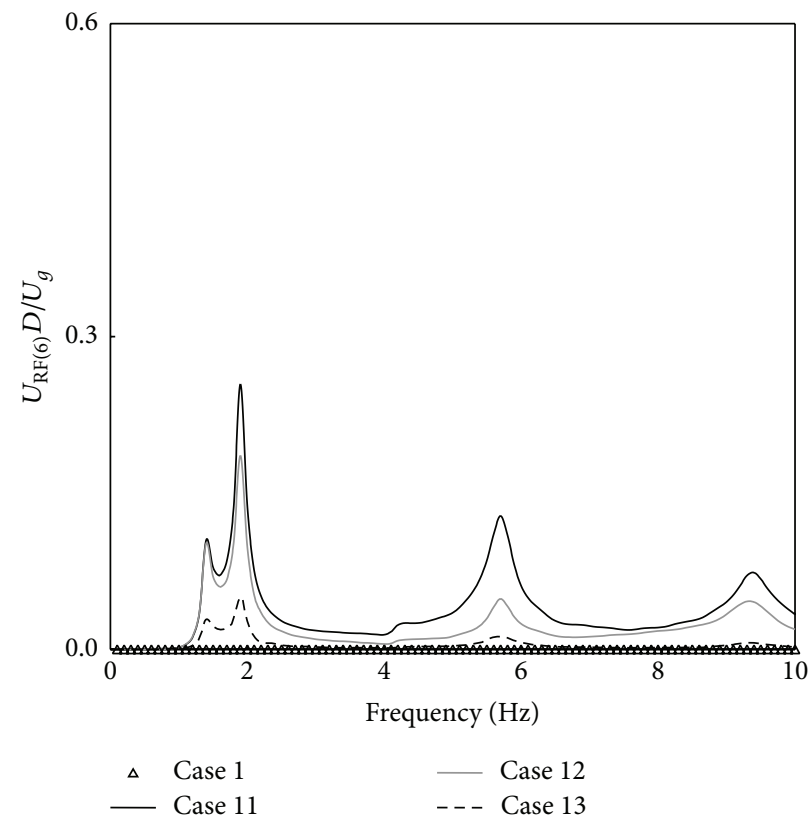

(a) Variation of distance $S$ (excited perpendicular to $x$-axis)
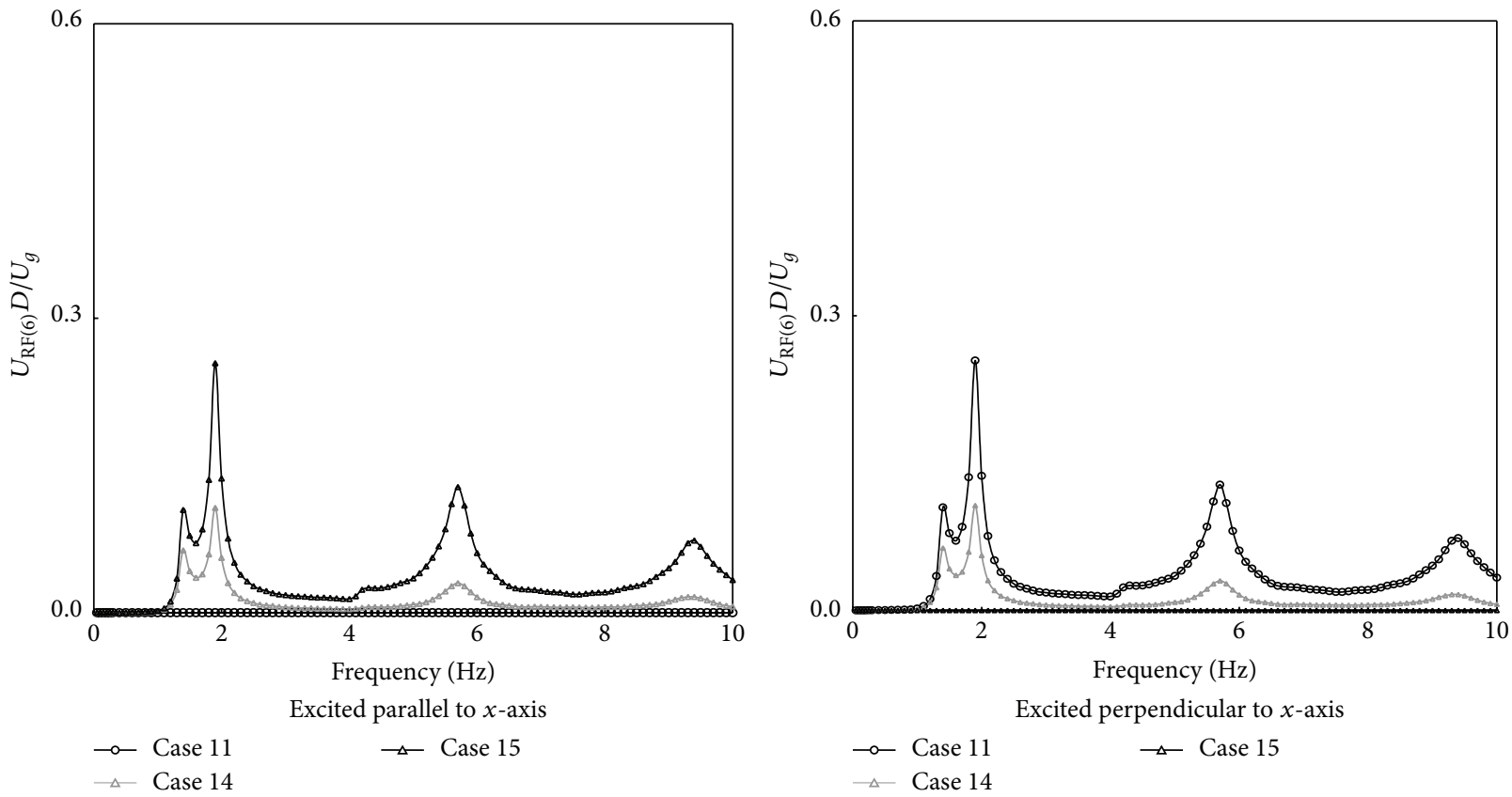

(b) Variation of angle $\beta$

FIGURE 11: Torsional response of the roof floor of the superstructure.

the four- and six-floor structures coincided with the first torsional natural frequencies of the six- and eight-floor structures. Figures 13(b) 13(c) show the torsional response of the structure affected by the adjacent structure; when the horizontal natural frequency of the adjacent structure coincided with the torsional natural frequency of the targeted structure, the torsional dynamic response of the targeted structure was more significant as can be seen in Figures 13(b) and 13(c).

\section{Conclusion}

The effects of soil structure interaction on torsional response of structure supported on asymmetric foundation under horizontal seismic excitation were assessed in this study. The results of the study may lead to the following conclusions:

(1) The torsional response can be generated for the structure supported on asymmetric foundation under 


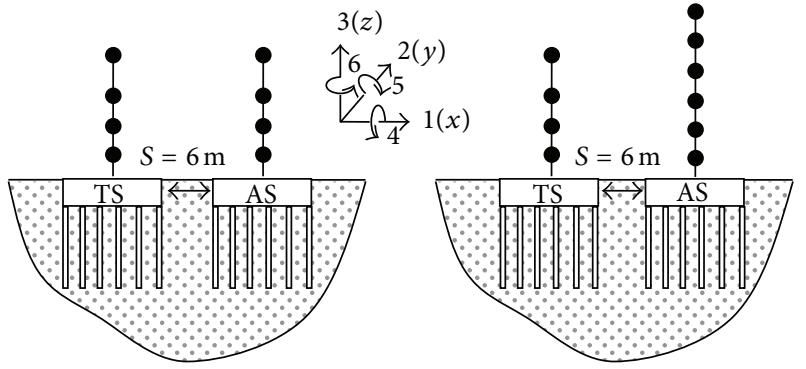

(a1) TS: 4-floor, AS: 4-floor (4_4) (a2) TS: 4-floor, AS: 6-floor (4_6)

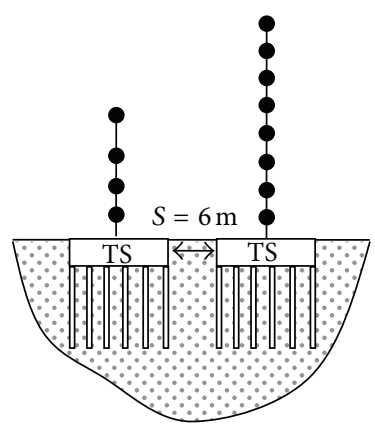

(a3) TS: 4-floor, AS: 8-floor (4_8)

(a) Case 16: 4-floor structure (TS) adjacent to structures

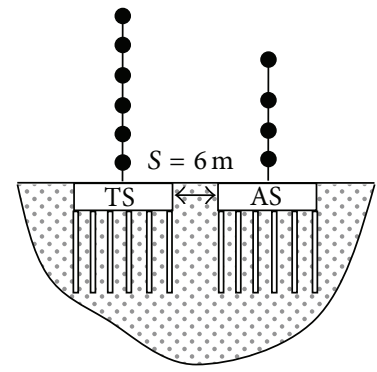

(b1) TS: 6-floor, AS: 4-floor (6_4)

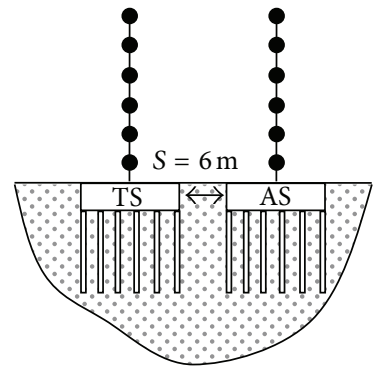

(b2) TS: 6-floor, AS: 6-floor (6_6)

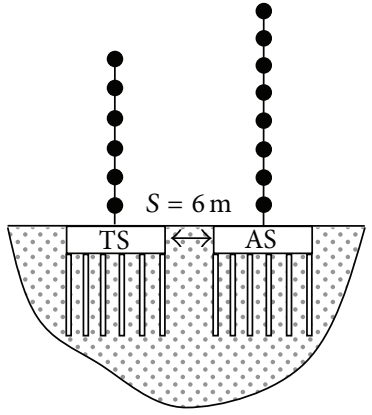

(b3) TS: 6-floor, AS: 8-floor (6_8)

(b) Case 17: 6-floor structure (TS) adjacent to structures

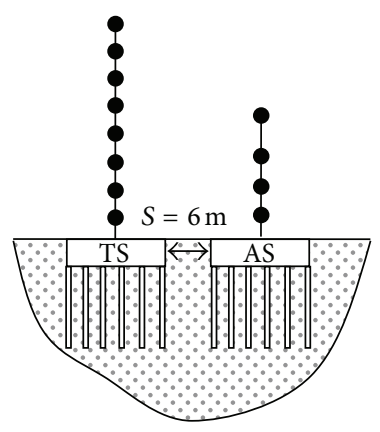

(c1) TS: 8-floor, AS: 4-floor (8_4)

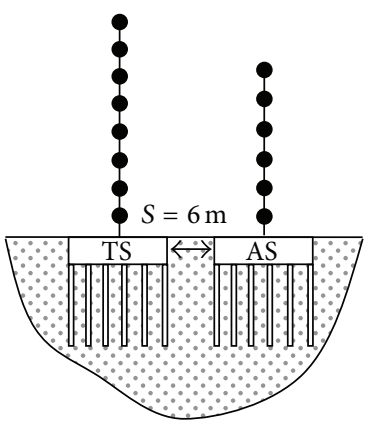

(c2) TS: 8-floor, AS: 6-floor (8_6)

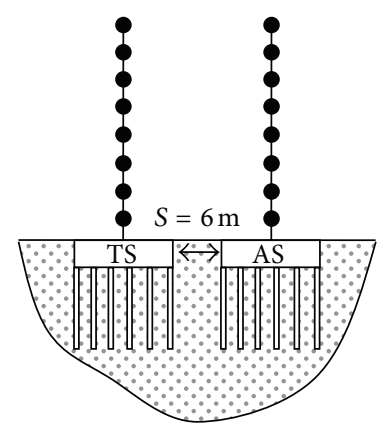

(c3) TS: 8-floor, AS: 6-floor (8_8)

(c) Case 18: 8-floor structure (TS) adjacent to structures

Figure 12: Existing structure adjacent to 4-, 6-, and 8-storey structure.

horizontal seismic excitation due to the eccentricity in the soil foundation system.

(2) For the structure supported by embedded-pile foundation with different pile lengths, the torsional response of the roof floor will be induced under horizontal seismic excitation as the mass center and the rigidity center of the soil foundation system with nonunique pile lengths do not coincide with each other, and the induced torsional response increases with the increase in the difference of pile lengths. Torsional response of the roof floor can also be observed for the structure supported by L shape or T shape embedded-pile foundation.
(3) As the movement of the soil around the foundation of the targeted structure can be restricted by the presence of an adjacent structure, motion characteristics of the soil around the targeted structure at different spatial location may be impacted in different extent by the adjacent structure. Thus, the torsional response of the roof floor of the targeted structure can be observed under horizontal seismic excitation. Especially when the horizontal natural frequency of the adjacent structure coincides with the torsional natural frequency of the targeted structure, the torsional dynamic response of the targeted structure can be affected significantly. 


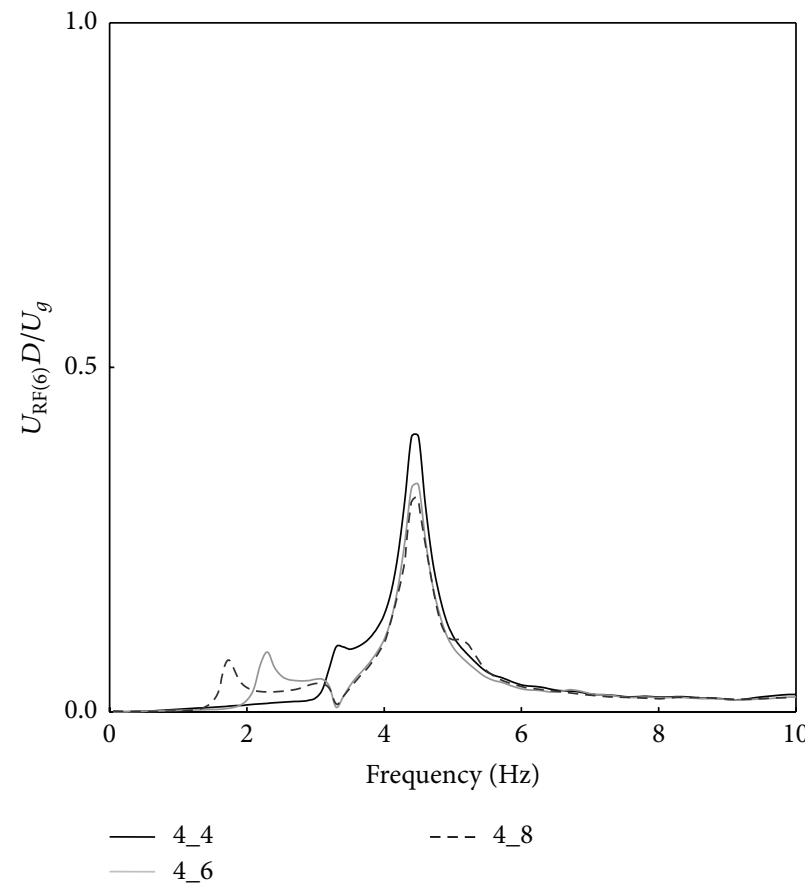

(a) Case 16: excited perpendicular to $x$ direction

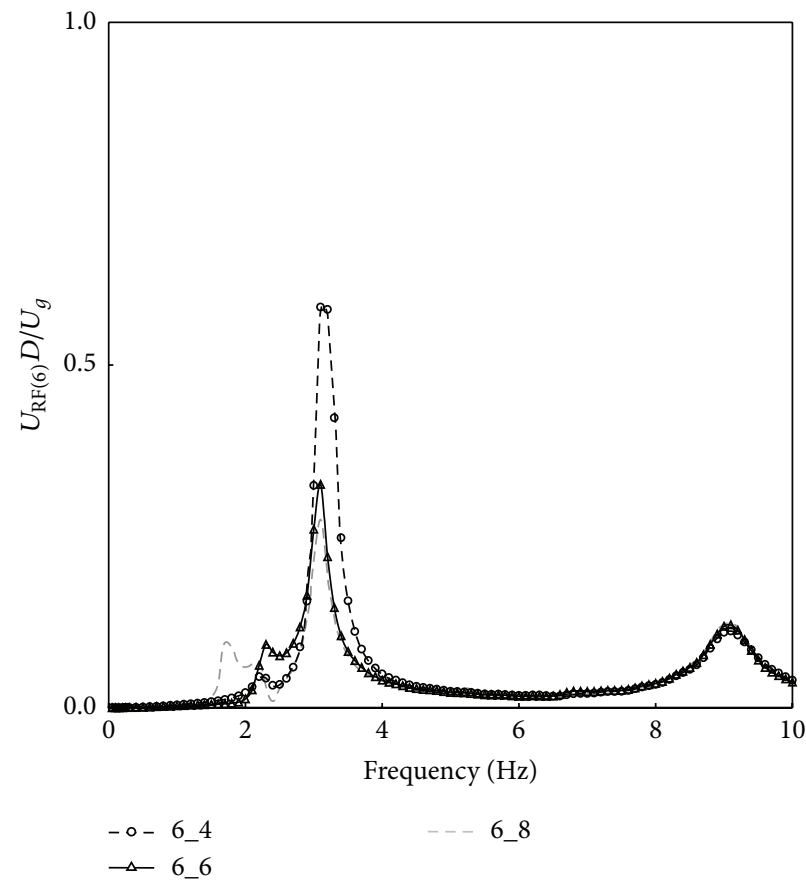

(b) Case 17: excited perpendicular to $x$ direction

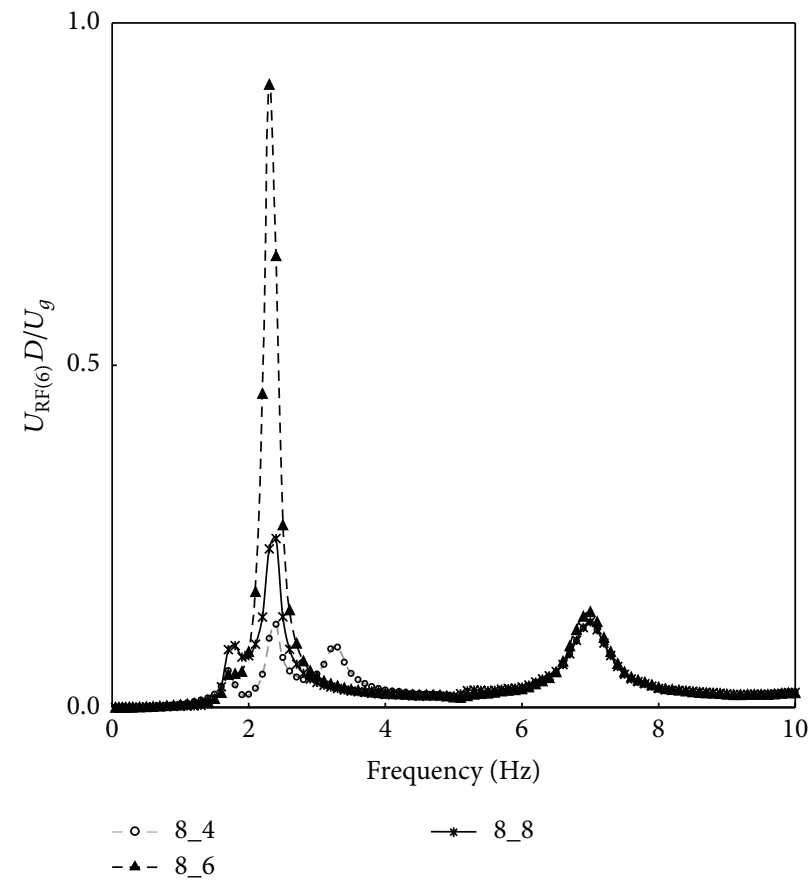

(c) Case 18: excited perpendicular to $x$ direction

FIGURE 13: Torsional response of the roof floor of the superstructure. 

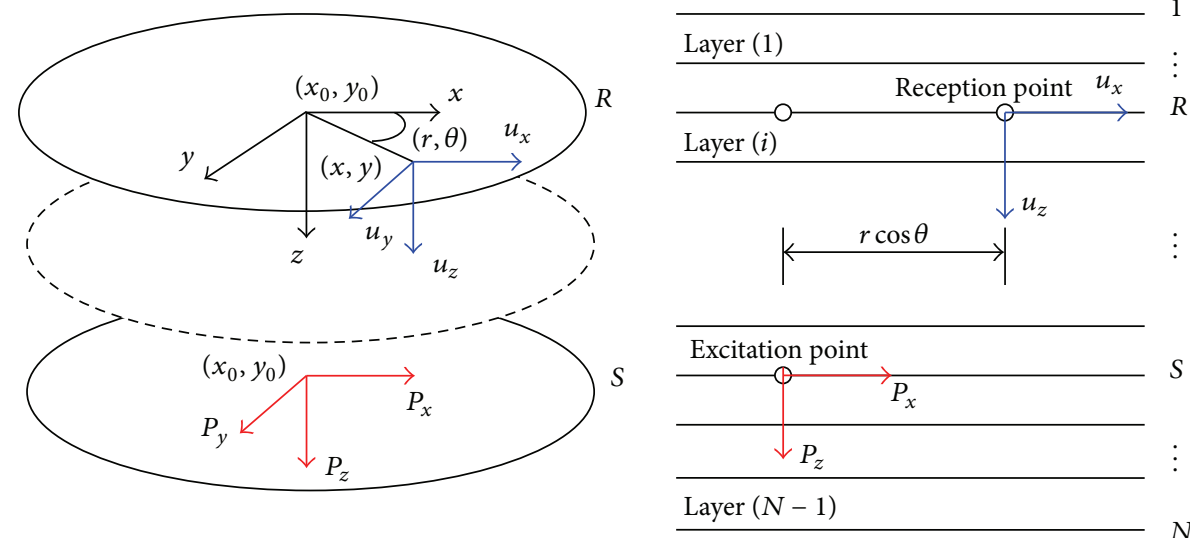

FIGURE 14: Geometric relationship between the excitation point and reception point in the thin layered method.

\section{Appendix}

\section{A. Formulation of Green's Function Used in the Thin Layer Method and Expression of the Paraxial Boundary Condition}

The displacement solution of a point located at $R$ surface for the load acting at $S$ surface (see Figure 14) includes

(1) point load solution $(r>0)$;

(2) disk load solution ( $r \rightarrow 0$, pile tip);

(3) ring load solution $(r \rightarrow 0$, pile shaft).

A.1. Point Load Solution. Let $u_{x}, u_{y}$, and $u_{z}$ displace components at elevation $R$ for a point load acting at elevation $S$. Green's function for point load is

$$
\begin{aligned}
& \left\{\begin{array}{l}
u_{x} \\
u_{y} \\
u_{z}
\end{array}\right\}_{R} \\
& =\left[\begin{array}{ccc}
V_{1} \cos 2 \theta+V_{2} & V_{1} \sin 2 \theta & V_{4} \cos \theta \\
V_{1} \sin 2 \theta & -V_{1} \cos 2 \theta+V_{2} & V_{4} \sin \theta \\
-V_{3} \cos \theta & -V_{3} \sin \theta & V_{5}
\end{array}\right]\left\{\begin{array}{l}
P_{x} \\
P_{y} \\
P_{z}
\end{array}\right\}_{S},
\end{aligned}
$$

where

$$
\begin{aligned}
V_{1}= & -\frac{1}{2 \pi} \sum_{k=1}^{2 N} \frac{X_{R k} X_{S k}}{D_{k \alpha}} \alpha_{k}^{2} F_{1}\left(\alpha_{k} r\right) \\
& +\frac{1}{4 \pi} \sum_{k=1}^{N} \frac{Y_{R k} Y_{S k}}{D_{k \beta}} F_{1}\left(\beta_{k} r\right) . \\
V_{2}= & \frac{1}{2 \pi} \sum_{k=1}^{2 N} \frac{X_{R k} X_{S k}}{D_{k \alpha}} \alpha_{k}^{2} F_{2}\left(\alpha_{k} r\right) \\
& +\frac{1}{4 \pi} \sum_{k=1}^{N} \frac{Y_{R k} Y_{S k}}{D_{k \beta}} F_{2}\left(\beta_{k} r\right)
\end{aligned}
$$

$$
\begin{aligned}
V_{3}= & \frac{1}{\pi} \sum_{k=1}^{2 N} \frac{Z_{R k} X_{S k}}{D_{k \alpha}} \alpha_{k}^{2} F_{3}\left(\alpha_{k} r\right) \\
V_{4}= & \frac{1}{\pi} \sum_{k=1}^{2 N} \frac{X_{R k} Z_{S k}}{D_{k \alpha}} \alpha_{k}^{2} F_{3}\left(\alpha_{k} r\right) \\
V_{5}= & \frac{1}{\pi} \sum_{k=1}^{2 N} \frac{Z_{R k} Z_{S k}}{D_{k \alpha}} \alpha_{k}^{2} F_{2}\left(\alpha_{k} r\right) \\
F_{1}(z)= & -\frac{2}{z^{2}}-i \frac{\pi}{z} H_{1}^{(2)}(z)+i \frac{\pi}{2} H_{0}^{(2)}(z) \\
F_{2}(z)= & -i \frac{\pi}{2} H_{0}^{(2)}(z) \\
F_{3}(z)= & -i \frac{\pi}{2} H_{0}^{(2)}(z) \\
D_{k \alpha}= & -\{X\}_{k}^{T}\left[E_{S}\right]\{X\}_{k}-\{Z\}_{k}^{T}\left[E_{P}\right]\{Z\}_{k} \\
& +\alpha_{k}^{2}\{X\}_{k}^{T}\left[A_{P}\right]\{X\}_{k} \\
& +\alpha_{k}^{2}\{Z\}_{k}^{T}\left[A_{S}\right]\{Z\}_{k} \\
D_{k \beta}= & \{Y\}_{k}^{T}\left[A_{S}\right]\{Y\}_{k} \\
r= & \sqrt{\left(x-x_{0}\right)^{2}+\left(y-y_{0}\right)^{2}} \\
\theta= & a \tan \left(\frac{y-y_{0}}{x-x_{0}}\right) \\
&
\end{aligned}
$$

$H_{v}^{(2)}(z)$ is the second Hankel function of order $v . \alpha_{k}$ is the $k$ th eigenvalue of characteristic equation (A.7). $\beta_{k}$ is the $k$ th eigenvalue of characteristic equation (A.8). $X_{k}, Z_{k}$ are the corresponding eigenvector of $\alpha_{k}$. $Y_{k}$ is the corresponding eigenvector of $\beta_{k}$. $X_{R k}$ is the $R$ th component of the eigenvector $X_{k} . Z_{R k}$ is the $R$ th component of the eigenvector $Z_{k}$. $Y_{R k}$ is $R$ th component of the eigenvector $Y_{k}$. 
A.2. Disk Load Solution. Let $u_{x}, u_{y}$, and $u_{z}$ displace components at elevation $R$ for a disk load acting at elevation $S$. Green's function for disk load is then

$$
\begin{aligned}
& \left\{\begin{array}{l}
u_{x} \\
u_{y} \\
u_{z}
\end{array}\right\}_{R} \\
& =\left[\begin{array}{lll}
V_{6}\left(r=r_{0}\right) & \\
& V_{6}\left(r=r_{0}\right) & \\
& & V_{7}\left(r=r_{0}\right)
\end{array}\right]\left\{\begin{array}{l}
P_{x} \\
P_{y} \\
P_{z}
\end{array}\right\}_{S},
\end{aligned}
$$

where

$$
\begin{aligned}
V_{6}= & \frac{1}{2 \pi} \sum_{k=1}^{2 N} \frac{X_{R k} X_{S k}}{D_{k \alpha}} \alpha_{k}^{2} F_{4}\left(\alpha_{k} r\right) \\
& +\frac{1}{4 \pi} \sum_{k=1}^{N} \frac{Y_{R k} Y_{S k}}{D_{k \beta}} F_{4}\left(\beta_{k} r\right) \\
V_{7}= & \frac{1}{\pi} \sum_{k=1}^{2 N} \frac{Z_{R k} Z_{S k}}{D_{k \alpha}} \alpha_{k}^{2} F_{4}\left(\alpha_{k} r\right) \\
F_{4}(z)= & -\frac{2}{z^{2}}-i \frac{\pi}{2} H_{1}^{(2)}(z) .
\end{aligned}
$$

$r_{0}$ is the radius of the disk.

A.3. Ring Load Solution. Consider the following:

$$
\begin{aligned}
& \left\{\begin{array}{l}
u_{x} \\
u_{y} \\
u_{z}
\end{array}\right\}_{R} \\
& =\left[\begin{array}{ccc}
V_{2}\left(r=r_{0}\right) & \\
& V_{2}\left(r=r_{0}\right) & \\
& & V_{5}\left(r=r_{0}\right)
\end{array}\right]\left\{\begin{array}{l}
P_{x} \\
P_{y} \\
P_{z}
\end{array}\right\}_{S},
\end{aligned}
$$

where

$$
\begin{aligned}
V_{2}= & \frac{1}{2 \pi} \sum_{k=1}^{2 N} \frac{X_{R k} X_{S k}}{D_{k \alpha}} \alpha_{k}^{2} F_{2}\left(\alpha_{k} r\right) \\
& +\frac{1}{4 \pi} \sum_{k=1}^{N} \frac{Y_{R k} Y_{S k}}{D_{k \beta}} F_{2}\left(\beta_{k} r\right) \\
V_{5}= & \frac{1}{\pi} \sum_{k=1}^{2 N} \frac{Z_{R k} Z_{S k}}{D_{k \alpha}} \alpha_{k}^{2} F_{2}\left(\alpha_{k} r\right) \\
F_{2}(z)= & -i \frac{\pi}{2} H_{0}^{(2)}(z) .
\end{aligned}
$$

$r_{0}$ is the radius of the ring.

A.4. Characteristic Equation of the Thin Layer Model as Shown in Figure 14. The characteristic equations of the thin layer model (shown in Figure 1) for Rayleigh (in-plane) and Love (anti-plane) waves are expressed by (A.7) and (A.8), respectively:

$$
\begin{aligned}
& \left.\left(\alpha^{2} \begin{array}{ll}
{\left[A_{P}\right]} & \\
& {\left[A_{S}\right]}
\end{array}\right]+\alpha\left[\begin{array}{ll}
{[B]^{T}} & {[B]} \\
& + \\
& {\left[E_{P}\right]}
\end{array}\right]\right)\left[\begin{array}{l}
X \\
Z
\end{array}\right]=\{0\}, \\
& \left(E_{S}{ }^{2}\left[A_{S}\right]+\left[E_{S}\right]\right)\{Y\}=\{0\},
\end{aligned}
$$

where $\left[A_{S}\right],\left[A_{P}\right],\left[E_{S}\right],\left[E_{P}\right]$, and $[B]$ are the matrices assembled by $\left[A_{S}\right]^{(i)},\left[A_{P}\right]^{(i)},\left[E_{S}\right]^{(i)},\left[E_{P}\right]^{(i)}$, and $[B]^{(i)}$, respectively, in the manner presented in

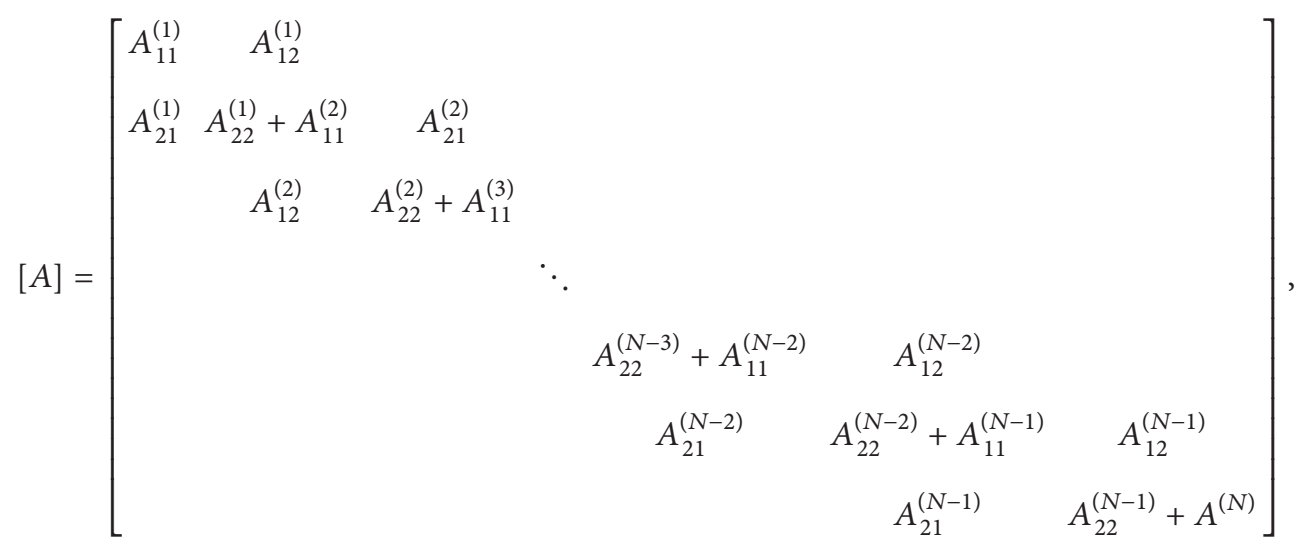


where $A^{(i)}$ is the matrix corresponding to the $i$ th soil layer and $A^{(N)}$ is matrix corresponding to the boundary condition. Consider the following:

$$
\begin{aligned}
& {\left[A_{S}\right]^{(i)}=\frac{G_{i} H_{i}}{6}\left[\begin{array}{ll}
2 & 1 \\
1 & 2
\end{array}\right],} \\
& {\left[A_{P}\right]^{(i)}=\frac{\left(\lambda_{i}+2 G_{i}\right) H_{i}}{6}\left[\begin{array}{ll}
2 & 1 \\
1 & 2
\end{array}\right] \text {, }} \\
& {\left[E_{S}\right]^{(i)}=\left[G_{S}\right]^{(i)}-\omega^{2}[M]^{(i)} \text {, }} \\
& {\left[G_{S}\right]^{(i)}=\frac{G_{i}}{H_{i}}\left[\begin{array}{cc}
1 & -1 \\
-1 & 1
\end{array}\right] \text {, }} \\
& {[M]^{(i)}=\frac{\rho_{i} H_{i}}{6}\left[\begin{array}{ll}
2 & 1 \\
1 & 2
\end{array}\right] \text {, }} \\
& {\left[E_{P}\right]^{(i)}=\left[G_{P}\right]^{(i)}-\omega^{2}[M]^{(i)},} \\
& {\left[G_{P}\right]^{(i)}=\frac{\left(\lambda_{i}+2 G_{i}\right)}{H_{i}}\left[\begin{array}{cc}
1 & -1 \\
-1 & 1
\end{array}\right] \text {, }} \\
& {[B]^{(i)}=\left[\begin{array}{cc}
-\frac{\left(\lambda_{i}-G_{i}\right)}{2} & \frac{\left(\lambda_{i}+G_{i}\right)}{2} \\
-\frac{\left(\lambda_{i}+G_{i}\right)}{2} & \frac{\left(\lambda_{i}-G_{i}\right)}{2}
\end{array}\right] \text {, }}
\end{aligned}
$$

where $\omega$ is the excited frequency of the load and $\lambda_{i}, G_{i}, H_{i}$, and $\rho_{i}$ are the Lame constant, shear elastic modulus, thickness, and density of the $i$ th soil layer, respectively.

$\alpha_{k}$ and $\left\{X_{k} Z_{k}\right\}^{T}(k=1,2 \ldots, 2 N)$ represent the eigenvalue and eigenvector, respectively, of characteristic equation (A.7).

$\beta_{k}$ and $\left\{Y_{k}\right\}^{T}(k=1,2 \ldots, N)$ represent the eigenvalue and eigenvector, respectively, of the characteristic equation (A.8).

\section{A.5. Paraxial Boundary}

(1) The boundary condition of (A.8) is as follows:

$$
\begin{aligned}
& A_{S}^{N}=-i \frac{G_{N}}{2} \frac{V_{S N}}{\omega}, \\
& E_{S}^{N}=i \omega \rho_{N} V_{S N} .
\end{aligned}
$$

(2) The boundary condition of (A.7) is shown as follows:

$$
\begin{aligned}
A_{S}^{N} & =i \frac{G_{N}}{2} \frac{V_{S N}}{\omega} \eta_{N}^{2}\left(\eta_{N}-2\right) \\
& =i \frac{\lambda_{N}+2 G_{N}}{2} \frac{V_{S N}}{\omega}\left(\eta_{N}-2\right), \\
A_{P}^{N} & =i \frac{G_{N}}{2} \frac{V_{S N}}{\omega}\left(1-2 \eta_{N}\right),
\end{aligned}
$$

$$
\begin{aligned}
& B^{N}=G_{N}\left(2-\eta_{N}\right), \\
& E_{S}^{N}=i \omega \rho_{N} V_{S N}, \\
& E_{P}^{N}=i \omega \rho_{N} V_{P N},
\end{aligned}
$$

where

$$
\begin{aligned}
\eta_{N} & =\frac{V_{P N}}{V_{S N}} \\
\lambda_{N} & =\frac{2 v_{N}}{1-2 v_{N}} G_{N} \\
G_{N} & =\rho_{N} V_{S N}^{2}
\end{aligned}
$$

$\lambda_{N}, G_{N}, \rho_{N}, \nu_{N}, V_{S N}$, and $V_{P N}$ are the Lame constant, shear elastic modulus, density, Poisson ratio, $S$-wave velocity, and $P$-wave velocity of the boundary, respectively.

\section{Conflict of Interests}

The authors declare that there is no conflict of interests regarding the publication of this paper.

\section{Acknowledgments}

The authors would like to gratefully acknowledge the financial support for this research provided by the National Natural Science Foundation of China (Grant no. 51308243), the National Basic Research Program (973) of China (Grant no. 2011CB013800), and the Fundamental Research Funds for the Central Universities: HUST (Grant no. 2015TS122).

\section{References}

[1] E. Rosenblueth and R. Meli, The 1985 Earthquake: Causes and Effects in Mexico City, vol. 5 of Concrete International, 1986.

[2] S. L. Wood, R. Stark, and S. A. Greer, "Collapse of eight-story RC building during 1985 Chile earthquake," Journal of Structural Engineering, vol. 117, no. 2, pp. 600-619, 1991.

[3] A. M. Chandler and G. L. Hutchinson, "Torsional coupling effects in the earthquake response of asymmetric buildings," Engineering Structures, vol. 8, no. 4, pp. 222-236, 1986.

[4] J. C. de la Llera and A. K. Chopra, "Accidental torsion in buildings due to stiffness uncertainty," Earthquake Engineering \& Structural Dynamics, vol. 23, no. 2, pp. 117-136, 1994.

[5] J. C. de la Llera and A. K. Chopra, "Accidental torsion in buildings due to base rotational excitation," Earthquake Engineering \& Structural Dynamics, vol. 23, no. 9, pp. 1003-1021, 1994.

[6] J. C. de la Llera and A. K. Chopra, "Evaluation of code accidental-torsion provisions from building records," Journal of Structural Engineering, vol. 120, no. 2, pp. 597-616, 1994.

[7] S. Nagarajaiah, A. M. Reinhorn, and M. C. Constantinou, "Torsion in base-isolated structures with elastomeric isolation systems," Journal of Structural Engineering, vol. 119, no. 10, pp. 2932-2951, 1993. 
[8] S. Nagarajaiah, A. M. Reinhorn, and M. C. Constantinou, "Torsional coupling in sliding base-isolated structures," Journal of Structural Engineering, vol. 119, no. 1, pp. 130-149, 1993.

[9] R. S. Jangid and T. K. Datta, "Nonlinear response of torsionally coupled base isolated structure," ASCE Journal of Structural Engineering, vol. 120, no. 1, pp. 1-22, 1994.

[10] R. S. Jangid and T. K. Datta, "Seismic response of torsionally coupled structure with elasto-plastic base isolation," Engineering Structures, vol. 16, no. 4, pp. 256-262, 1994.

[11] A. Tena-Colunga and C. Zambrana-Rojas, "Dynamic torsional amplifications of base-isolated structures with an eccentric isolation system," Engineering Structures, vol. 28, no. 1, pp. 7283, 2006.

[12] A. Tena-Colunga and L. Gómez-Soberón, “Torsional response of base-isolated structures due to asymmetries in the superstructure," Engineering Structures, vol. 24, no. 12, pp. 1587-1599, 2002.

[13] A. Tena-Colunga and J. L. Escamilla-Cruz, "Torsional amplifications in asymmetric base-isolated structures," Engineering Structures, vol. 29, no. 2, pp. 237-247, 2007.

[14] E. Çelebi and A. N. Gündüz, "An efficient seismic analysis procedure for torsionally coupled multistory buildings including soil-structure interaction," Turkish Journal of Engineering and Environmental Sciences, vol. 29, no. 3, pp. 143-157, 2005.

[15] M. Nasser, "Seismic response of R/C frames considering dynamic soil-structure interaction," in Proceedings of the 18th International Conference on the Application of Computer Science and Mathematics in Architecture and Civil Engineering, Weimar, Germany, July 2009.

[16] C.-C. Lin, J.-F. Wang, and C.-H. Tsai, "Dynamic parameter identification for irregular buildings considering soil-structure interaction effects," Earthquake Spectra, vol. 24, no. 3, pp. 641666, 2008.

[17] S. Mohasseb and B. Abdollahi, "Soil-structure interaction analyses using cone models," Journal of Seismology and Earthquake Engineering, vol. 10, no. 4, pp. 167-174, 2009.

[18] T. Balendra, C. W. Tat, and S. L. Lee, "Modal damping for torsionally coupled buildings on elastic foundation," Earthquake Engineering \& Structural Dynamics, vol. 10, pp. 735-756, 1982.

[19] A. M. Chandler and G. L. Hutchinson, "Code design provisions for torsionally coupled buildings on elastic foundation," Earthquake Engineering \& Structural Dynamics, vol. 15, no. 4, pp. 517536, 1987.

[20] A. M. Chandler and G. L. Hutchinson, "Parametric earthquake response of torsionally coupled buildings with foundation interaction," Soil Dynamics and Earthquake Engineering, vol. 6, no. 3, pp. 138-148, 1987.

[21] K. S. Sivakumaran, M.-S. Lin, and P. Karasudhi, "Seismic analysis of asymmetric building-foundation systems," Computers and Structures, vol. 43, no. 6, pp. 1091-1103, 1992.

[22] K. S. Sivakumaran and T. Balendra, "Seismic analysis of asymmetric multistorey buildings including foundation interaction and P- $\Delta$ effects," Engineering Structures, vol. 16, no. 8, pp. 609$625,1994$.

[23] J. Lysmer, R. M. Tabatabaie, F. Tajirian, S. Vahdani, and F. Ostadan, "SASSI-a system for analysis of soil-structure interaction," Report UCB/GT/81-02, University of California, Berkeley, Calif, USA, 1981.

[24] E. Kausel, "An explicit solution for the green function for dynamic loads in layered media," Tech. Rep. R81-13, Department of Civil and Environmental Engineering, Massachusetts Institute of Technology, Cambridge, Mass, USA, 1981.
[25] S. Hull, Dynamic loads in layered halfspaces [Ph.D. thesis], Massachusetts Institute of Technology, 1985.

[26] S. Hull and E. Kausel, "Dynamic loads in layered halfspace," in Proceedings of the 5th ASCE/EMD Specialty Conference, pp. 201204, Laramie, Wyo, USA, August 1984.

[27] Architectural Institute of Japan, An Introduction to Dynamic Soil-Structure Interaction, Gihodoshppan, Tokyo, Japan, 1996. 


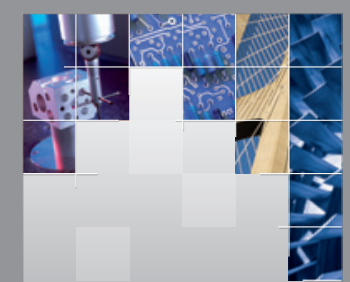

\section{Enfincering}
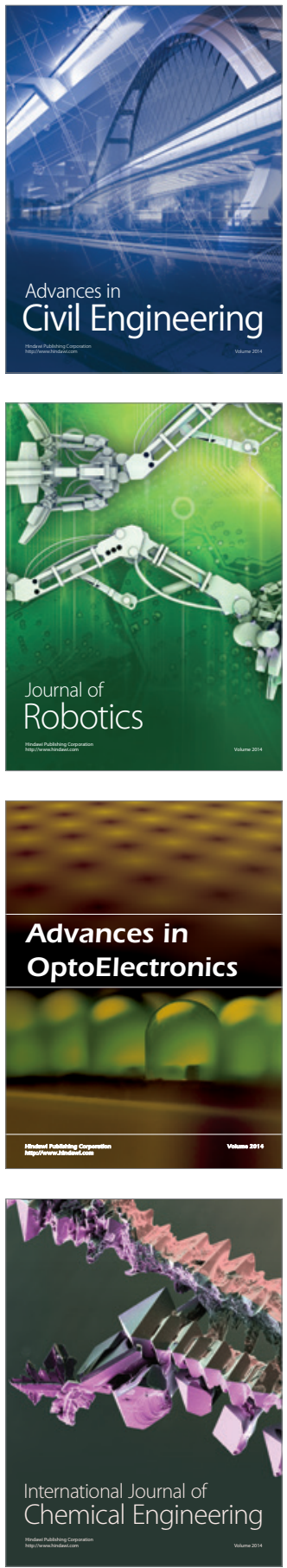

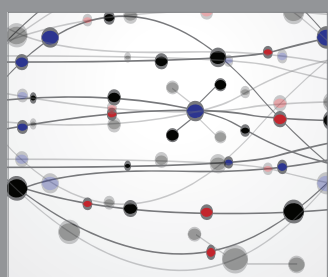

The Scientific World Journal

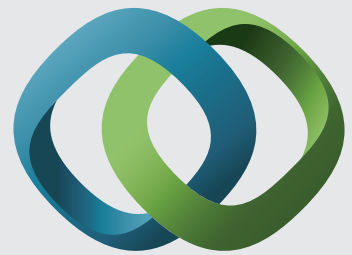

\section{Hindawi}

Submit your manuscripts at

http://www.hindawi.com
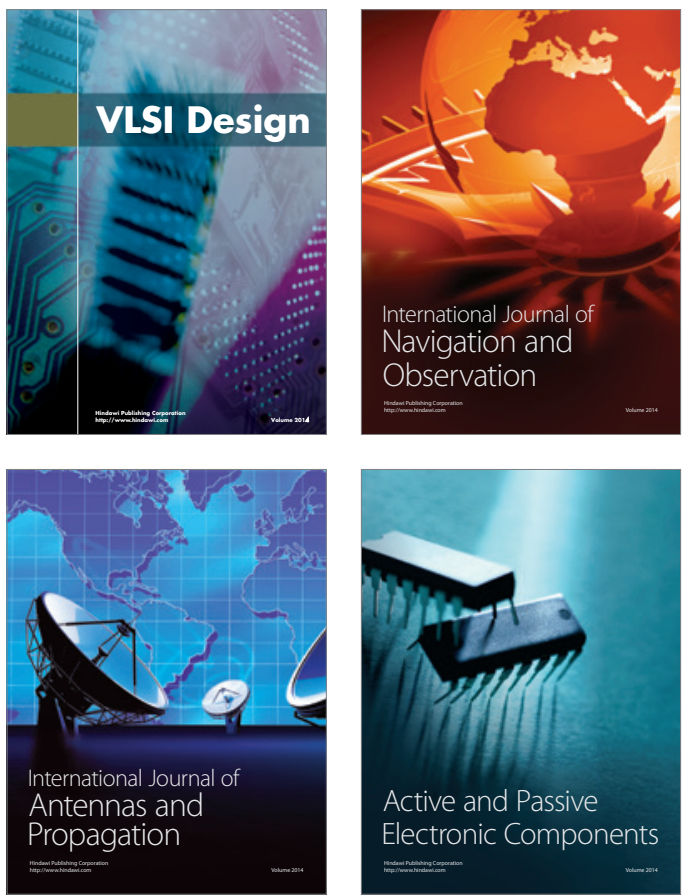
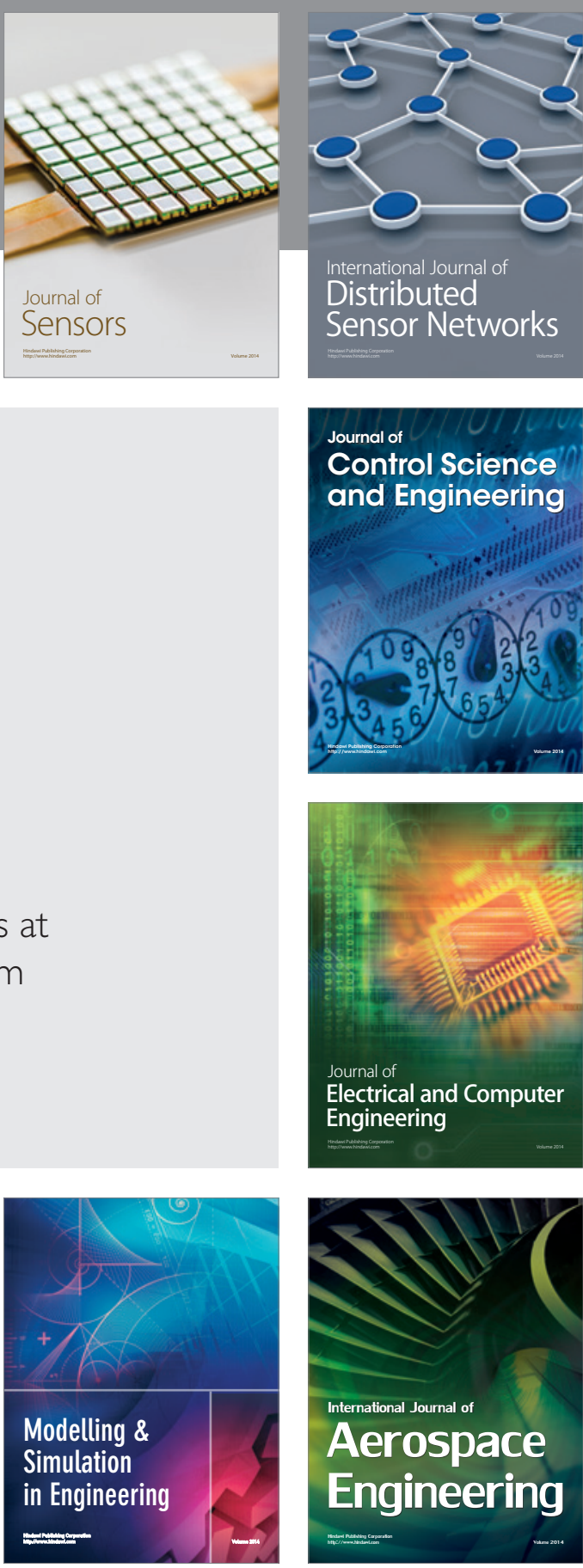

International Journal of

Distributed

Sensor Networks

Journal of

Control Science

and Engineering
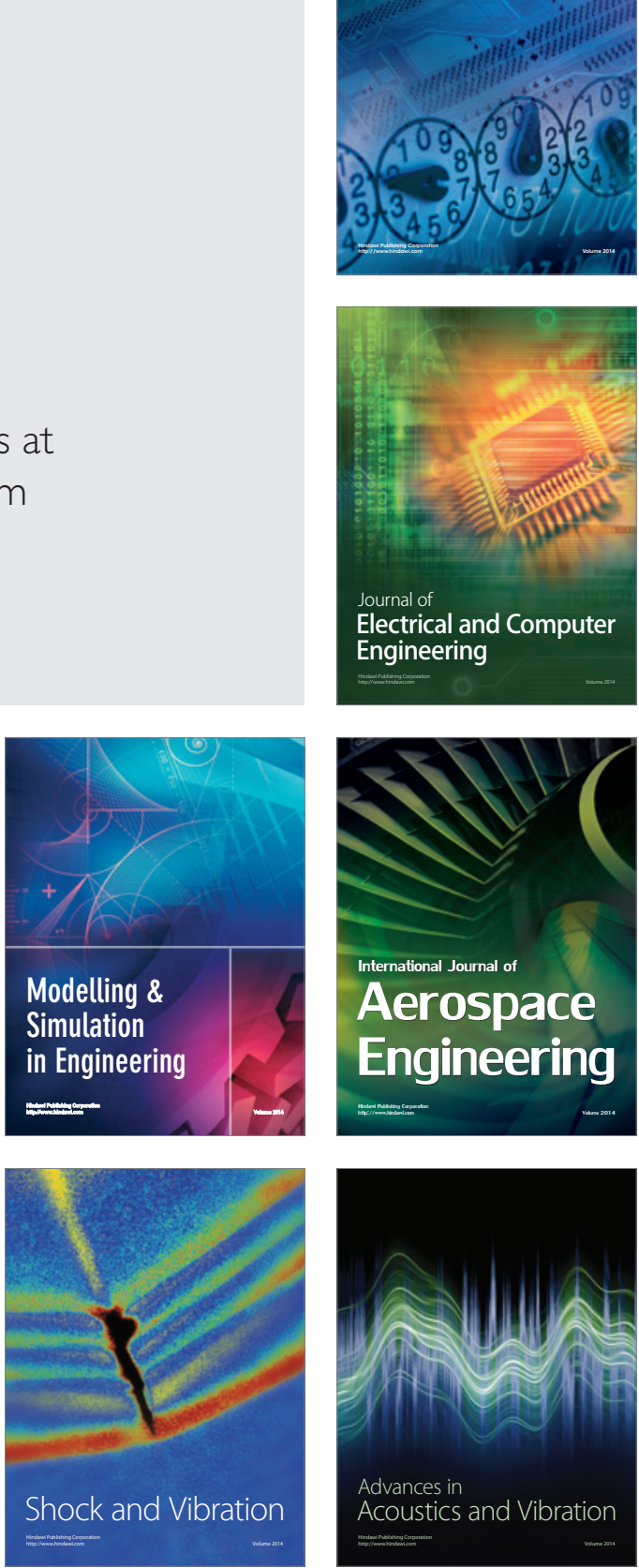